\title{
El mundo de las mutuales étnicas en Tucumán. Relaciones inter-asociativas, liderazgos y vínculos con el poder público entre el último tercio del siglo XIX y comienzos del XX
}

\section{The realm of ethnic mutual societies in Tucumán. Inter-associative relations, leaderships and ties to public power between the last third of the $19^{\text {th }}$ century and the beginning of the $20^{\text {th }}$}

\author{
Vanesa Teitelbaum \\ Consejo Nacional de Investigaciones Científicas y Técnicas \\ Universidad Nacional de Tucumán \\ Instituto Superior de Estudios Sociales
}

(Argentina)

vteitel@yahoo.com

\section{Resumen}

El artículo estudia el mundo asociativo y, en especial, el mutualismo, entendido como una de las principales expresiones étnicas en el ámbito urbano. En especial, analiza la conformación de una trama de relaciones inter-asociativas, la construcción de liderazgos al interior de las mutuales y los vínculos con los poderes públicos locales que se revelaron y conformaron al calor de reuniones formales de la vida mutual -como asambleas y sesiones de comisiones directivas-, celebraciones de las sociedades étnicas y recepciones instrumentadas para agasajar a los viajeros europeos que visitaban la provincia. Estas problemáticas, muy poco exploradas para el caso de Tucumán, serán investigadas desde un enfoque de historia social, abierto a su vez a los fenómenos culturales y políticos. De acuerdo con esa perspectiva, se privilegia el examen de 
San Miguel de Tucumán, capital y centro comercial y administrativo de la provincia, durante el periodo formativo de las mutuales, que podemos situar, aproximadamente, entre el último tercio del siglo XIX y comienzos del XX. Para realizar el trabajo, recurrimos a un conjunto de fuentes: principalmente documentos de las mutuales de inmigrantes, como estatutos, reglamentos, actas de asambleas y libros de comisiones directivas, complementados con los datos obtenidos de la prensa local.

Palabras Clave: Mutualismo - Dirigentes étnicos - Asambleas - Fiestas - Visitas

\begin{abstract}
The present article explores the realm of associations, especially mutualism, as one of the main ethnical expressions within the urban environment of Tucumán. Mainly, it addresses the configuration of interassociative connections, the building up of leadership within mutual societies, and their ties with local public power, as they were forged and revealed in assemblies, board-committee sessions and other forms of typical meetings of mutual life, such as festivities of ethnic societies or honor receptions to European travelers. Such issues -which have hardly been examined in Tucumán- will be researched from social history perspectives, whilst remaining open to cultural and political phenomena. Therefore, we focus the study on San Miguel de Tucumán, the capital, administrative and commercial center of the province, during the formative period of mutual societies, which is comprised approximately between the last third of 19 th century and the early decades of the 20th. To carry out this task, we turned primarily to documents from the immigrant's mutual associations, such as statutes, regulations, assembly minutes and board commission books, all of which was complemented by data obtained from the local press.
\end{abstract}

Key Words: Mutualism - Ethnic leaders - Assemblies - Celebrations - Visits

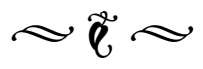

\section{Introducción}

Desde mediados del siglo XIX y, en especial, a partir del último tercio de dicha centuria, numerosos contingentes de inmigrantes llegaron a Argentina en busca de un futuro mejor. La mayoría se instaló en Buenos Aires, la capital del país, y en las provincias más dinámicas de la economía nacional situadas en la zona del Litoral y la Pampa Húmeda. Aunque éstas fueron las áreas privilegiadas en la recepción de extranjeros provenientes de ultramar, el grueso del territorio argentino también recibió el influjo del fenómeno inmigratorio. Tal fue el caso de la provincia de Tucumán, localizada en el noroeste argentino, donde la llegada de inmigrantes trajo aparejada, como en el resto del país, el surgimiento y desarrollo de una floreciente trama asociativa. ${ }^{1}$ Dentro del denso tejido

1. La década de 1880 marcó el inicio de la gran afluencia inmigratoria en Tucumán. Entre 1895 y 1914 llegaron a la provincia 41.773 inmigrantes provenientes de ultramar y se registró un saldo migratorio internacional de más de 25.000 personas. Entre 1890-1900 el ingreso 
de asociaciones se destacaron las mutuales, creadas con el propósito central de proteger a sus miembros ante los perjuicios causados por la enfermedad, la invalidez y el fallecimiento. Con ese fin, estipularon socorros que incluían invariablemente asistencia médica, entrega de medicamentos y una determinada cobertura para afrontar los costos del sepelio.

Además, las asociaciones de ayuda mutua impulsaron numerosas prácticas de sociabilidad, cultura y educación a través de conferencias, veladas, tertulias literariomusicales, bailes y festivales organizados para recaudar fondos destinados a solventar emprendimientos medulares de la vida asociativa, como la construcción de un local, un panteón en el cementerio o un establecimiento educativo. Asimismo, las fiestas se convocaban para conmemorar las principales efemérides del calendario patriótico y/o religioso de las asociaciones de inmigrantes.

Paralelamente, las asociaciones étnicas y especialmente sus dirigentes desempeñaron un papel fundamental en la recepción de

de extranjeros de ultramar fue para Tucumán 8.652 en valores absolutos y $1.33 \%$ los valores relativos Tucumán/ Argentina, para 1900-1910 fueron 19.021 (valores absolutos) y $1.07 \%$ los valores relativos Tucumán/ Argentina, entre 1910-1914 las cifras fueron 19.121 en valores absolutos y $1.58 \%$ los valores relativos Tucumán/ Argentina. Sigo el análisis de ORTÍZ DE D'ARTERIO, Patricia, Las migraciones internacionales en la provincia de Tucumán, Serie Tesis, Instituto de Estudios Geográficos, Facultad de Filosofía y Letras, Universidad Nacional de Tucumán, 2004, pp. 37 y 43. Los grupos de extranjeros más numerosos fueron los españoles e italianos. Otras colectividades importantes en la época fueron la francesa, alemana, austro-húngara, rusa y otomana. BOLOGNINI, Víctor Hugo y CURIA DE VILLECCO, María Elena, Del otro lado del mar. Tucumán, destino final, Facultad de Filosofía y Letras, Instituto de Historia y Pensamiento Argentino, Tucumán, 2006, p. 37. renombradas figuras, generalmente europeos, que visitaron la provincia en su calidad de diplomáticos, industriales o representantes culturales.

Una de las hipótesis que guía este trabajo sostiene que las reuniones formales de la vida mutual -como asambleas y sesiones de la comisión directiva- revelaron, al tiempo que contribuyeron, a la conformación de una trama de relaciones inter-asociativas, a la construcción de liderazgos al interior de las mutuales y a robustecer los vínculos con los poderes públicos locales. Otro supuesto que subyace en el estudio propone que estos lazos se potenciaron mediante las celebraciones de las sociedades étnicas y las actividades instrumentadas durante la estadía de visitantes ilustres. En ese marco, tiene sentido pensar que eran los líderes étnicos, figuras visibles de la puesta en marcha y conducción de los festejos, quienes más se beneficiaban de tales intercambios al entablar relaciones con gobernantes, grupos económicos y otros dirigentes comunitarios.

Estas problemáticas serán analizadas en el presente trabajo, planteado desde un enfoque de historia social, abierto a su vez a los fenómenos culturales y políticos. Desde esa óptica, y apoyándome principalmente en una metodología de tipo cualitativa, analizo un conjunto de fuentes. En especial, examinamos los documentos de las mutuales de inmigrantes que incluyen estatutos, reglamentos, actas de asambleas y libros de comisiones directivas. Los datos obtenidos en estos materiales se completaron y complementaron con la información recabada mediante el examen sistemático de la prensa, en especial, de $E l$ Orden, el diario más importante de Tucumán durante la época estudiada. 
Como es sabido, el estudio sobre el asociacionismo étnico en Argentina constituye un campo de análisis fértil que produjo valiosas contribuciones centradas, especialmente, en las provincias que recibieron mayor aporte inmigratorio. Son numerosos los problemas que llamaron la atención de los historiadores especializados en el fenómeno inmigratorio y contribuyeron a enriquecer esta investigación de múltiples maneras. ${ }^{2}$ Sin ánimo de referirme a todos ellos, me gustaría mencionar algunos que fueron de gran utilidad para este trabajo, como los de Fernando Devoto sobre las sociedades mutuales italianas en Argentina, sus funciones, composición social, grupos dirigentes, festividades, ideologías y su relación con la política local, ${ }^{3}$ y el trabajo conjunto y pionero del autor y Alejandro Fernández acerca de las asociaciones étnicas españolas e italianas, en el cual ahondaron

\section{Algunos de los trabajos que nos sirvieron especialmente fueron: DEVOTO, Fernando, "La experiencia mutualista italiana en Argentina: un balance", en DEVOTO, Fernando y MíGUEZ, Eduardo J. (compiladores) Asociacionismo, trabajo e identidad étnica. Los italianos en América Latina en una perspectiva comparada, Centro de Estudios Migratorios Latinoamericanos, Centro Studi Emigrazione e Instituto de Estudios Históricos y Sociales, Buenos Aires/Roma, 1992, pp. 169-185; MOYA, José C., Primos y extranjeros. La inmigración española en Buenos Aires, Emecé, Buenos Aires, 2004 y OTERO, Hernán, "El asociacionismo francés en la Argentina. Una perspectiva secular”, en Estudios Interdisciplinarios de América Latina y el Caribe, Tel Aviv, 2010, V. XXI, No 2, pp. 123-150. Disponible en: <http://www7.tau.ac.il/ojs/index.php/eial/article/ view/32/16>}

\section{En especial, DEVOTO, Fernando, "Participación y} conflictos en las sociedades italianas de socorros mutuos", en DEVOTO, Fernando y ROSOLI, Gianfausto (editores) La inmigración italiana en la Argentina, Biblos, Buenos Aires, Colección La Argentina plural, 2000, pp. 141-164 y DEVOTO, Fernando, Historia de los italianos en la Argentina, Biblos, Buenos Aires, Colección La Argentina plural, 2008 [1 $1^{\text {a }}$ edición 2006]. en las características de sus socios y líderes. ${ }^{4}$ Asimismo, resultó sugerente el aporte de Xosé Manoel Núñez Seixas sobre los modelos de liderazgos en comunidades inmigradas, en el cual el autor recupera una definición del líder étnico y explora las múltiples problemáticas inherentes a la naturaleza y tipos de liderazgo, a sus fuentes de poder y al perfil social de los líderes. ${ }^{5}$ Otra propuesta valiosa para este artículo fue la de Jon Gjerde acerca de la identidad complementaria que combina "lealtad al grupo étnico y al grupo nacional en una dinámica que se refuerza a sí misma y que engarza el pluralismo en el tejido nacional tal como los inmigrantes y sus líderes los comprenden". ${ }^{6}$ Finalmente, recuperamos las preocupaciones que recorren los trabajos recientes sobre el asociacionismo, referidas al papel de las negociaciones, las prácticas de sociabilidad y la conformación de culturas asociativas, liderazgos, redes y trayectorias al interior de las asociaciones. ${ }^{7}$

4. DEVOTO, Fernando y FERNÁNDEZ, Alejandro, "Mutualismo étnico, liderazgo y participación política. Algunas hipótesis de trabajo", en ARMUS, Diego (compilador) Mundo urbano y cultura popular, Sudamericana, Buenos Aires, 1990.

5. NÚNEZ SEIXAS, Xosé Manoel, "Modelos de liderazgos en comunidades inmigradas. Algunas reflexiones a partir de los españoles en América”, en BERNASCONI, Alicia y FRID, Carina (editoras) De Europa a las Américas. Dirigentes y liderazgos (1880-1960), Biblos, Colección La Argentina plural, Buenos Aires, 2006, pp. 17-41.

6. GJERDE, Jon, "Identidades múltiples y complementarias. Inmigrantes, liderazgos étnicos y el Estado en Estados Unidos", en BERNASCONI, Alicia y FRID, Carina, De Europa a las Américas..., Op. Cit., pp. 63-79.

7. En especial, FERNÁNDEZ, Sandra y VIDELA, Oscar (compiladores) Ciudad oblicua. Aproximaciones e intérpretes de la entreguerra rosarina, La Quinta Pata y Camino Ediciones, Rosario, 2008; GONZÁLEZ BERNALDO, Pilar, "El momento mutualista en la 
Para el caso específico de Tucumán contamos con valiosos aportes sobre diversos aspectos relacionados con la inmigración, originados desde la década de 1970 en el Instituto de Historia y Pensamiento Argentino de la Facultad de Filosofía y Letras de la Universidad Nacional de Tucumán. ${ }^{8}$ Asimismo, disponemos de estudios posteriores que se sumaron a estos esfuerzos y permitieron enriquecer el conocimiento del tema en la provincia. ${ }^{9}$

formulación de un sistema de protección social en Argentina: socorro mutuo y prevención subsidiada a comienzos del siglo XX, en Revista de Indias, Madrid, 2013, V. LXXIII, pp. 157-192. Disponible en: <http:// revistadeindias.revistas.csic.es/index.php/revistadeindias/ article/view/921/994>, doi:10.3989/revindias.2013.007; BRAVO, María Celia y FERNÁNDEZ, Sandra (coordinadoras) Formando el espacio público: asociacionismos y politica. Siglos XIX y XX, Editorial de la Universidad Nacional de Tucumán, Tucumán, 2014, pp. 7-24. Un balance en torno a la historiografía sobre el asociacionismo en Argentina en BRAVO, María Celia y FERNÁNDEZ, Sandra, "El prisma de lo político. Las asociaciones en el espacio público argentino, siglo XX”, en BRAVO, María Celia y FERNÁNDEZ, Sandra Formando el espacio público..., Op. Cit., pp. 7-24.

\section{CENTRO DE HISTORIA Y PENSAMIENTO} ARGENTINO, La inmigración en Argentina, Tucumán, Facultad de Filosofía y Letras, Tucumán, 1979; GARCÍA DE SALTOR, Irene, CURIA DE VILLECCO, María Elena, BOLOGNINI, Víctor Hugo, UGARTE DE GALLO, Alicia y PIOSSEK DE ZUCCHI, Lucía Transformaciones en la Argentina Aluvial, en PROGRAMA DEL CONSEJO DE INVESTIGACIONES DE LA UNIVERSIDAD NACIONAL DE TUCUMÁN,“La Argentina ante transformaciones del mundo contemporáneo desde la perspectiva del NOA, Serie 2, Facultad de Filosofía y Letras, Instituto de Historia y Pensamiento Argentino, Tucumán, 1995; CURIA DE VILLECCO, María E. y BOLOGNINI, Víctor Hugo Inmigración en Tucumán, Facultad de Filosofía y Letras, Instituto de Historia y Pensamiento Argentino, Tucumán, 1991 y BOLOGNINI, Víctor Hugo y CURIA DE VILLECCO, María Elena Del otro lado del mar..., Op. Cit.

\section{Por ejemplo, ORTÍZ DE D’ARTERIO, Patricia,}

Desde hace algunos años, además, comenzó a desarrollarse una línea de trabajo centrada en el asociacionismo que arrojó fecundos resultados en terrenos vinculados con la salud y la beneficencia, la cultura, las asociaciones católicas y las expresiones corporativas de cañeros y empresarios azucareros. ${ }^{10} \mathrm{~A}$ su vez, adquirió impulso el examen de las asociaciones obreras y sus prácticas de sociabilidad, política, protesta, cultura y recreación. ${ }^{11}$

Las migraciones internacionales..., Op. Cit; NAESSENS, Sergio Francisco, La inmigración en Argentina en el siglo XX. Análisis de casos: japoneses, belgas y coreanos en Tucumán, Centro de Estudios de Asia y Âfrica, Facultad de Filosofía y Letras, Universidad Nacional de Tucumán, Tucumán, 2004 y FEYLYNG, Mariana, "La inmigración francesa temprana en Tucumán: 1830-1880", en Travesía, Tucumán, 2004, N 7/8, pp. 73-101. Disponible en: <http://www.travesia-unt.org.ar/pdf/travesia78_3.pdf>

10. GARGIULO, Cecilia, La Sociedad de Beneficencia en la política social. Tucumán, 1874-1917, Tesis Doctoral, Universidad Nacional de Tucumán, 2012: VIGNOLI, Marcela Sociabilidad y cultura politica. La Sociedad Sarmiento de Tucumán, 1880-1914, Prohistoria Ediciones, Rosario, 2015; SANTOS LEPERA, Lucía, "Asociacionismo y prácticas católicas en los años treinta: asociacionismo y prácticas católicas en los años treinta: la Acción Católica tucumana y la configuración del laicado", en VIDAL, Gardenia y BLANCO, Jessica (compiladoras) Estudios de la historia de Córdoba en el siglo XX, T. II, Ferreyra Editor, Córdobam 2010, pp. 19-36; LANDABURU, Alejandra, "Organizaciones de la sociedad civil, trabajadores y empresarios azucareros. Tucumán, fines del siglo XIX y principios del XX", ponencia presentada en XJornadas Interescuelas/Departamentos de Historia, Universidad Nacional de Rosario, Rosario, 2005; BRAVO, María Celia Campesinos, azúcar y política: cañeros, acción corporativa y vida politica en Tucumán (1895-1930), Prohistoria, Rosario, 2008 y LENIS, María, Empresarios del azúcar. Corporaciones, politica y discursos. Tucumán (1894-1923), Imago Mundi, Buenos Aires, 2016.

11. Algunos trabajos en esa línea son, TEITELBAUM, Vanesa, "El anarquismo en Tucumán: expresiones de protesta y rituales obreros, 1900-1912", en Izquierdas, Santiago, 2016, N² 28, pp. 66-93 Disponible en: <http://www.scielo.cl/scielo.php?script=sci_ 
En el contexto de estas preocupaciones, este trabajo presenta una aproximación al mundo asociativo $y$, en especial, al mutualismo, entendido como una de las principales manifestaciones étnicas en el ámbito de urbano. ${ }^{12}$ Para ello, presta especial atención a temáticas muy poco exploradas para el ámbito provincial, referidas a las relaciones de las mutuales entre sí y con el poder público, al tiempo que indaga la conformación de liderazgos al interior de las asociaciones y su proyección al resto de la sociedad local. La investigación abarca la ciudad de San Miguel de Tucumán, capital y centro comercial y administrativo de la provincia, durante el periodo de formación de las mutuales que

arttext\&pid=S0718-50492016000300003;

TEITELBAUM, Vanesa, "Veladas literario-musicales y manifestaciones públicas en la construcción del Primero de Mayo en Tucumán (Argentina), 18971925”, en Esboços - Revista do Programa de PósGraduação em História da UFSC, Florianapólis, 2015, V.XXII, N³3, pp. 170-197. Disponible en: <http:// dx.doi.org/10.5007/2175-7976.2014v22n33p170>; TEITELBAUM, Vanesa, "Movilizaciones, dirigentes y conformación de una trama asociativa en el mundo del trabajo artesanal (Tucumán, 1890-1910)”, en Theomai. Estudios Críticos sobre sociedad y desarrollo, Bernal, 2015, pp. 123-145 Disponible en: <http://revista-theomai. unq.edu.ar/NUMERO_31/6.Teitelbaum.pdf>; TEITELBAUM, Vanesa, "El Centro Cosmopolita de Trabajadores: un espacio de referencia del movimiento obrero en el norte argentino en los umbrales del siglo XX”, en Estudios Sociales, Santa Fe, 2011, No 40, pp. 145174 Disponible en: <http://bibliotecavirtual.unl.edu.ar/ ojs/index.php/EstudiosSociales/article/view/2676/3834>; TEITELBAUM, Vanesa, "Los centros obreros como ámbitos de cultura, protesta y política (Tucumán, 18951910)", en AA. VV. La clase obrera y el Centenario-1910trabajos de investigación, Central de Trabajadores de la Argentina (CTA) y Programa de Investigación sobre el Movimiento de la Sociedad Argentina (PIMSA), CTA Ediciones, Buenos Aires, 2011.

12. BJERG, María, Historias de la inmigración en la Argentina, Edhasa, Temas de la Argentina, Buenos Aires, 2009, p. 45. podemos situar, aproximadamente, entre el último tercio del siglo XIX y comienzos del $\mathrm{XX}$, aunque se ha privilegiado el análisis de los años 1910-1916, en tanto constituye una de las etapas de mayor interés signada por los preparativos para conmemorar los festejos de los centenarios. ${ }^{13}$

\section{La formación de mutuales étnicas}

En este primer apartado queremos proponer algunas líneas vinculadas con los procesos de conformación de las sociedades de socorro mutuo compuestas por extranjeros. Para ello, debemos comenzar con las asociaciones pioneras del mutualismo en Tucumán, lo cual nos lleva directamente a la Sociedad Extranjera, fundada en 1868. A diferencia del grueso de mutuales étnicas que agrupaba a sus socios según el lugar de origen, esta asociación reunió inmigrantes de distintas nacionalidades y según los registros de inscripción de socios para el periodo 1899-1911, predominaban

13. Agradezco la advertencia de uno de los árbitros anónimos de este artículo sobre cómo la consulta de fuentes documentales coincidentes con un periodo especialmente celebratorio en Argentina (el ciclo del centenario 1910-1916) posiblemente contribuyó a invisibilizar las tensiones desarrolladas a fines del siglo XIX con relación a las fiestas de inmigrantes. Al respecto, Lilia Ana Bertoni demuestra en su libro como "el crecimiento de las fiestas extranjeras en el espacio simbólico amenazaba con tapar las fiestas patrias propias que, confrontadas con ellas, parecían vacías y sin calor popular. La amenaza de disgregación y de desaparición de lo nacional, ya agitada por el alud de inmigrantes, aparecía también en la manifestación de las lealtades patrias" en BERTONI, Lilia Ana, Patriotas, cosmopolitas y nacionalistas. La construcción de la nacionalidad argentina a fines del siglo XIX, Fondo de Cultura Económica, Buenos Aires, 2001, p. 88. 
franceses e italianos, que en su mayoría eran comerciantes. ${ }^{14}$

Una década después, en 1878 , se estableció la Asociación de Socorros Mutuos y Beneficencia Española, siguiendo el impulso de un grupo de inmigrantes (comerciantes, empresarios, periodistas y docentes) bajo el liderazgo de Romero Jiménez. ${ }^{15}$ La mutual española, la cual con el tiempo alcanzaría un lugar preponderante en el universo étnico tucumano, se había formado con el propósito esencial de brindar ayuda mutua y beneficencia, al tiempo que contribuir al sostenimiento del Hospital Español de Buenos Aires. ${ }^{16}$ Siguiendo los objetivos genéricos de las mutuales, la Asociación de Socorros Mutuos y Beneficencia Española se propuso otorgar socorro a sus miembros ante las enfermedades y los accidentes que podían sufrir mientras trabajaban. Además, como era lo usual en una

14. LANDABURU, Alejandra, "Organizaciones de la sociedad civil en Tucumán a fines del siglo XIX y comienzos del XX: las sociedades mutuales", en Actas VI Jornadas La Generación del Centenario y su Proyección en el Noroeste Argentino. 1900-1950, Tucumán, Centro Cultural Alberto Rougés, Fundación Miguel Lillo, Tucumán, 2006.

15. De acuerdo a la información existente, sabemos que los españoles se habían reunido en el ámbito típico de encuentro de lo comunidad española, el Café Colón, ubicado al frente de la Plaza Independencia, principal paseo público de la ciudad. Allí, desempeñó un papel preponderante el conocido dirigente español Romero Jiménez, que vivía en Buenos Aires y estaba de visita en la provincia. Ver: ORTÍZ REINA, Ana María, "Inmigrantes españoles en Tucumán. La Asociación Española de Socorros Mutuos y Beneficencia de Tucumán y la de Tafí Viejo", en PEDICONE DE PARELLADA, Elena (directora y compiladora) Espacio de Sinergia entre España y Tucumán, Universidad Nacional de Tucumán, Tucumán, 2013, p. 183.

16. LANDABURU, Alejandra, “Organizaciones de la sociedad civil...”, Op. Cit. mutual étnica, los requisitos para acceder a la categoría de socio consistían en:

1. Ser español o hijo de españoles;

2. Gozar de buena reputación moral

3. No padecer enfermedad alguna;

4. Contar de quince a sesenta años de edad;

5. Ejercer alguna honesta profesión, arte $\mathrm{u}$ oficio. $^{17}$

Quienes cumplían con las condiciones arriba señaladas recibían el calificativo de socios efectivos y, en consecuencia, eran merecedores de las ayudas previstas para los casos de enfermedad que consistían en asistencia de un médico, 1 peso boliviano diario y medicinas. Asimismo, podían contar con la cobertura de gastos ante el fallecimiento. Para aquellos individuos que superasen los 60 años de edad la categoría prevista por la mutual era la de socios titulares, título que les otorgaba el derecho de recibir el derecho de honras y lugar póstumo pero no podían acceder al resto de los socorros. Por último, interesa mencionar que la asociación establecía la posibilidad de admitir como socios "sin exigírseles derecho de ingreso, a los miembros de sociedades análogas establecidas en las Repúblicas cisplatinas, cuyos reglamentos acuerden esta misma concesión" ${ }^{18}$

17. Archivo Histórico de Tucumán (en adelante AHT), Reglamento de la Asociación de Socorros Mutuos y Beneficencia Española en Tucumán, 1880.

18. Reglamento de la Asociación de Socorros Mutuos y Beneficencia Española en Tucumán, en AHT. Como sugiere Landaburu, "estos acuerdos representaban un gran beneficio para sus miembros, ya que aunque viajaran o cambiaran de residencia seguían protegidos, lo que significaba no solo asistencia médica y medicamentos sino el derecho de ser enterrados en los panteones de las Sociedades Españolas, como sustituto del suelo patrio. En esa línea la Sociedad Española de Tucumán formó parte de la Confederación de Sociedades Españolas de Socorros Mutuos de Argentina y de América del 
Coincidente con el año de creación de la Asociación de Socorros Mutuos y Beneficencia Española se fundó en la ciudad de San Miguel de Tucumán la Sociedad Unione e Mutuo Soccorso. De forma similar al resto de las mutuales, la asociación italiana se constituyó con el propósito principal de otorgar ayuda mutua ante los casos de enfermedad. Paralelamente, buscaba propiciar la fraternidad y solidaridad con toda la sociedad italiana.

Como era costumbre en el universo del mutualismo, tanto las discusiones políticas como las de naturaleza religiosa estaban expresamente prohibidas en la vida de la mutual. Sin embargo, esto no quiere decir que los integrantes de la comunidad inmigrante italiana se mantuvieran alejados del debate público. Por el contrario, el interés en la vida política local y los lazos establecidos con políticos y gobernantes formaron parte de la práctica de varios miembros de la colectividad, lo cual trajo aparejado no pocos conflictos. ${ }^{19}$

Según lo estipulado en sus estatutos, todos los italianos o hijos de italianos podían formar parte de la sociedad. En ese contexto y para poder ser considerados como socios debían

Sur”, LANDABURU, Alejandra, "Organizaciones de la sociedad civil...", Op. Cit.

19. Una muestra en ese sentido se reflejó con la visita del cónsul francés a la provincia y el banquete organizado por miembros de la comunidad italiana organizados en el Comitato di Beneficenza. Según la acusación de un sector de la colectividad inmigrante que se expresaba en el periódico satírico Il Soffietto, los individuos pertenecientes a esta asociación habían aprovechado dicha ocasión para hacer política, al excluir a numerosos y renombrados miembros de la comunidad italiana y no invitar al gobernador Lucas Córdoba, así como a los funcionarios de su gobierno y la prensa oficial a dicho evento. Al respecto, Il Soffietto. Periodico Settimanale-Umoristico di Battaglie, Tucumán, 7/7/1906. demostrar buena reputación y abonar la cuota mensual que variaba según la edad. Para aquellos que tuvieran entre 15 a 30 años de edad debían abonar 3 pesos moneda nacional, quienes se encontraran en la franja etaria de 31 a 40 años tenían que pagar 4 pesos moneda nacional y los de 41 a 50 años 5 pesos moneda nacional.

Interesa destacar que la asociación mutual italiana seguía un sentido patriótico, evidenciado desde el momento mismo de su fundación en las palabras de uno de los directivos de la institución, el vice-presidente provisorio Antonio A. Moris, quien afirmaba "presidir una asamblea de italianos en tierra extranjera que representa dignamente a madre patria”. ${ }^{20}$ El lugar esencial brindado por la Sociedad Unione e Mutuo Soccorso a fomentar los sentimientos patrióticos hacia Italia se expresó también en el emblema elegido por la mutual: la bandera tricolor italiana. ${ }^{21}$

La preocupación por conservar los vínculos de identificación y pertenencia con Italia se manifestaban en múltiples instancias de la vida asociativa. Así, por ejemplo, renegar de la nacionalidad italiana era considerado motivo de expulsión. De esta forma, los socios no podían adoptar la nacionalidad argentina. Otro aspecto que consideraron prioritario para estimular los sentimientos de identidad con la patria de origen fue la educación y, especialmente, la transmisión del idioma

20. BOLOGNINI, Víctor Hugo y CURIA DE

VILLECCO, María Elena Del otro lado del mar..., Op. Cit., p. 221.

21. AHT, Statuto-Regolamento de la Societá Italiana Unione e Mutuo Soccorso, Tipografía de la Patria Italiana, Buenos Aires, 1886. 
italiano. En ese contexto, podemos situar el proyecto presentado en 1895 por parte de la asociación italiana para construir una escuela. ${ }^{22}$

Sin duda, la edificación de escuelas fue una consigna compartida por el grueso de las mutuales étnicas. Mediante la educación impartida a los hijos y descendientes de inmigrantes era posible difundir, mantener $\mathrm{y}$ fomentar las tradiciones, los valores, los hábitos, los contenidos y símbolos de la cultura propia del país de origen. En esa línea, la enseñanza del idioma era una cuestión central. Al respecto, podemos mencionar el caso de la mutual de inmigrantes franceses, la Societé Française Industrielle de Secours Mutuels, fundada en 1879 y que en 1904 resolvió crear la École Enfantine Exclusivement Française de enseñanza elemental. Precisamente, el tema del idioma fue central en la creación del establecimiento. Un grupo sostenía que la educación debía impartirse en castellano y en francés, mientras otro sector pensaba que la educación únicamente debía darse en francés. Finalmente, esta fue la postura que prosperó. Otro tópico enérgicamente discutido entonces fue la relación del establecimiento educativo con el Consejo de Educación de la Provincia,ya que la escuela se encontraba bajo dependencia de dicho Consejo, con el mismo rango de las escuelas fiscales. Resulta importante advertir que este vínculo estuvo signado por conflictos, como el desplegado entre un grupo de socios de la mutual y uno de los integrantes del Consejo Provincial de Educación, el militante

22. Por esta vía se cumplía con lo estipulado en "el Art. $3^{\circ}$ del Estatuto de 1896: La asociación italiana debe responder también a la implantación y manutención de la escuela italiana”. CURIA DE VILLECCO, María Elena y BOLOGNINI, Víctor Hugo, Inmigración en Tucumán..., Op. Cit., pp. 112-113. católico José Fierro, a quien responsabilizaron por el fracaso de la escuela. ${ }^{23}$

Como ya fue señalado por la historiografía sobre el tema, en consonancia con el afán de los grupos de poder político por construir y afianzar la idea de nación y de Estado argentino, la enseñanza en las escuelas constituyó una cuestión ríspida que generó tensiones y enfrentamientos. Esta lucha se desplegó, sobre todo, con los establecimientos educativos creados por las colectividades de extranjeros que podían dificultar la empresa encaminada a conformar, difundir e instaurar el uso de un idioma común, tradiciones, símbolos y fiestas patrias, en el marco de los esfuerzos por armar una idea de nacionalidad argentina. ${ }^{24}$

Ya para terminar, es importante recordar que los estatutos y reglamentos de las asociaciones étnicas seguían un patrón común y contenían

23. LANDABURU, Alejandra, "Organizaciones de la sociedad civil...", Op. Cit.

24. Las transformaciones desarrolladas en el ámbito escolar a raíz de la decisión de otorgar un carácter nacional a la educación, aspiración que trajo aparejado el combate a otras expresiones que disputaban el lugar de la enseñanza entre los niños, como fue el caso de las escuelas de las comunidades de inmigrantes, es explicada en BERTONI, Lilia Ana, Patriotas, cosmopolitas y nacionalistas..., Op. Cit. Sobre el tema se puede ver también: FRID, Carina, "Las opciones educativas de la comunidad italiana en Rosario: las escuelas mutualistas y el colegio Salesiano (1880-1920)", en DEVOTO, Fernando y MÍGUEZ, Eduardo J. (compiladores) Asociacionismo, trabajo e identidad étnica..., Op. Cit., pp. 101-114; FAVERO, Luigi, "Las escuelas de las sociedades italianas en Argentina (1866-1914), en DEVOTO, Fernando y ROSOLI, Gianfausto (editores) La inmigración italiana..., Op. Cit., pp. 165-207 y OTERO, Hernán Gustavo, "Las escuelas étnicas de la comunidad francesa. El caso argentino, 1880-1950", en Anuario de Estudios Americanos, Sevilla, 2011, V. LXVIII, N 1, pp. 163-189. Disponible en: <http://estudiosamericanos.revistas.csic.es/index.php/ estudiosamericanos/article/view/536/540> 
disposiciones semejantes. ${ }^{25}$ Sin embargo, tal uniformidad no opacaba las diferencias que podían existir entre las mutuales, como las surgidas en torno a las condiciones de nacionalidad de los socios. En esa dirección, la mutual francesa contempló el socorro a "los suizos y belgas que por su limitado número no pueden formar una sociedad", ${ }^{26}$ tal como sucedía en otras asociaciones de ayuda mutua francesas de Argentina. ${ }^{27}$

En síntesis, diversos colectivos de inmigrantes, entre los que se destacaban españoles, italianos y franceses, constituyeron asociaciones de ayuda mutua para obtener servicios de atención a la salud y conseguir cobertura ante el fallecimiento. En un contexto caracterizado por la debilidad del Estado en el terreno de políticas laborales, sociales y sanitarias, las mutuales se posicionaron como instituciones sumamente atractivas, especialmente para las comunidades de inmigrantes que debían adaptarse a un nuevo país. ${ }^{28}$

25. Al respecto, DEVOTO, Fernando y FERNÁNDEZ, Alejandro, "Mutualismo étnico...", Op. Cit., p. 137.

\section{AHT, Estatutos de la Sociedad de Socorros Mutuos Sociedad Francesa de Socorros Mutuos, 1893.}

27. Una característica semejante para Santa Fe se observa en: MICHELETTI, María Gabriela, "Asociacionismo y espíritu étnico en Santa Fe a fines del siglo XIX”, ponencia presentada en $X$ Jornadas Interescuelas/ Departamentos de Historia, Universidad Nacional de Rosario, Rosario, 2005.

28. En el periodo estudiado surgieron diversas asociaciones formadas por colectivos de inmigrantes. A continuación presento un listado que elaboré a partir de la lectura sistemática de la prensa periódica (en especial, El Orden, para el periodo 1897-1917 y La Gaceta, desde 1912), el cual incluye a las siguientes mutuales: Sociedad Extranjera (1868), Asociación de Socorros Mutuos y Beneficencia Española (1878), Sociedad Unione e Mutuo Soccorso (1878), Sociedad Helvética (1885), Sociedad Francesa de Socorros Mutuos (1893), Sociedad Israelita (1910), luego denominada Sociedad Unión Israelita

\section{Explorando el funcionamiento de las mutuales. El caso de la asociación española}

Las actas de asambleas, libros de comisiones directivas y actas de comisiones especiales conformadas por las sociedades de socorros mutuos constituyen fuentes muy ricas para el estudio del asociacionismo. A través de estos documentos, es posible aproximarnos al funcionamiento de estas instituciones, desentrañar aspectos inherentes a su vida asociativa, reconstruir los vínculos que entablaron con otras sociedades y recuperar las relaciones -de amistad, camaradería o de conflicto- que podían mantener los integrantes de una misma mutual.

A modo ilustrativo, me detendré en el caso de la Sociedad Española de Socorros Mutuos. La lectura de sus actas de asambleas y sesiones de comisión directiva reveló que en sus reuniones se debatieron los temas típicos de las mutuales, centrados en la distribución de ayudas a los socios enfermos y en la presentación de comprobantes de gastos ocasionados por accidentes, invalidez y subsidios concedidos a socios. Del examen de estas fuentes se desprende, a su vez, la importancia de la Sociedad Española de Socorros Mutuos en

Tucumán (1911), Sociedad Israelita Otomana (1917), posteriormente refundada como Asociación Israelita Sefaradí de Beneficencia (1921), Sociedad Sirio Libanesa (1925) y Asociación Libanesa de Socorros Mutuos (1937). Además, desde la primera década del siglo XX se establecieron centros culturales, sociales y educativos de inmigrantes como la Casa de España, la Casa de Francia, la Alianza Francesa y la Casa de Italia y asociaciones formadas según criterios regionales como el Centro Asturiano, el Centro Catalá de Cultura y el Centro Artístico Valenciano. 
la época, la influencia de las relaciones interasociativas, comerciales y políticas y el esfuerzo de la mutual por alcanzar la unificación con otras sociedades española. ${ }^{29}$

Como era usual en el mundo asociativo mutual cada vez que una sociedad elegía una nueva comisión directiva informaba a otras asociaciones de dicha elección. Así, por ejemplo, en 1916, la Sociedad Española de Socorros Mutuos se comunicó con el Centro Asturiano y con la Sociedad Italiana de Socorros Mutuos para avisarles de la elección de su nueva comisión directiva. ${ }^{30}$ De esta forma, se incentivaba el desarrollo de un tejido asociativo en el cual intervenían distintas sociedades étnicas y donde se apuntalaban especialmente los vínculos entre las asociaciones de inmigrantes de un mismo país, en este caso, las españolas.

Tiene sentido proponer que estos vínculos se reforzaban en el contexto de celebraciones fundamentales del calendario cívico y patriótico. Tal fue el caso de los preparativos para conmemorar el Primer Centenario de la Independencia en nuestro país que iniciaron un año antes, es decir en 1915. En ese momento, la Sociedad Española de Socorros Mutuos recibió una carta enviada por la Sociedad Sarmiento, principal asociación cultural de Tucumán durante el periodo estudiado, en la cual invitaba a todos los presidentes $\mathrm{y}$ directores de sociedades argentinas $\mathrm{y}$ extranjeras de San Miguel de Tucumán para participar de "la reunión que tendrá lugar en el local de la misma el día 24 del presente mes

29. Por ejemplo, Archivo de la Sociedad Española (en adelante ASE), Acta No 18, Sesión Ordinaria, Libro de Comisiones Directivas, Año 1915.

30. ASE, Acta No 66, Sesión Ordinaria, Libro de Comisiones Directivas, 14/08/1916. a las cinco de la tarde con objeto de cambiar y acordar ideas y propósitos tendientes a la digna conmemoración del Centenario de la Independencia". ${ }^{31}$

También el gobierno provincial convocó a la Sociedad Española de Socorros Mutuos a participar de los distintos actos previstos para la celebración del Centenario de la Independencia. En esa dirección, podemos mencionar la invitación que en marzo de 1916 efectuó a la mutual la Comisión Provincial del Centenario para que ésta formara parte de la procesión cívica programada por el Centenario de la Independencia. Asimismo, el Ministerio de Gobierno y Obras Públicas citó a la sociedad española para que asistiese a la misa solemne que se efectuaría en la Iglesia de San Francisco con vistas a la celebración del Primer Centenario. $^{32}$

Por su parte, la Sociedad Española de Socorros Mutuos se propuso coordinar las acciones dirigidas a lograr una participación óptima en los festejos señalados. Con ese fin, llamó a la prensa, a los socios de la mutual y al resto de la comunidad española a una reunión que tendría lugar en su sede el día 8 de julio a las 13:30. El propósito era partir desde allí en corporación a la manifestación popular prevista para el mismo día, la cual consistía en un desfile por la Casa de la Independencia. ${ }^{33}$ Además, como parte de los esfuerzos dirigidos a conmemorar el Centenario de la Independencia, la Sociedad Española de Socorros Mutuos decidió mejorar

31. ASE, Acta No 17, Sesión Ordinaria, Libro de Comisiones Directivas, Año 1915.

32. ASE, Acta No 44, Sesión Ordinaria, Libro de Comisiones Directivas, 24/03/1916.

33. ASE, Acta No 57, Sesión Ordinaria, Libro de Comisiones Directivas, 26/06/1916. 
su equipamiento y adquirir una biblioteca y muebles (tales como una mesa grande, una docena de sillas, un sofá y dos sillones) para su secretaría. ${ }^{34}$ Estas mejoras se realizaron en el marco de la inminente visita de los delegados de otras asociaciones españolas que habían comprometido su asistencia al local de la Sociedad Española.

Para finalizar me gustaría plantear algunas cuestiones. La primera, que los dirigentes provenían, en su mayoría, del mundo del comercio, la industria y las profesiones liberales, albergaron estrechas conexiones con el poder público y revelaron una activa participación en la escena pública. De esta forma, es factible vincular el perfil de la dirigencia mutual étnica tucumana con el de los líderes mutuales de inmigrantes de otras ciudades argentinas, tal como demuestran Devoto y Fernández al estudiar la composición de los dirigentes de las colectividades española e italiana, donde prevalecieron comerciantes, empresarios $\mathrm{y}$ profesionales liberales, "sobre todo si se tienen en cuenta únicamente los cargos principales de las instituciones (presidente, vicepresidente, secretario, tesorero). Paralelamente, los autores proponen la existencia de estrechas vinculaciones "entre sus dirigentes y el resto de las entidades representativas de la colectividad (bancos, periódicos, clubes sociales, hospitales, cámaras de comercio, etc.)" ${ }^{35}$ En el caso que nos ocupa, es factible afirmar que varios de los hombres que condujeron la mutual italiana ocuparon cargos en la provincia y participaron en distintas asociaciones. Trayectorias como la de Antonio A. Moris resultaron ilustrativas en

34. ASE, Acta No 50, Sesión Ordinaria, Libro de Comisiones Directivas, 11/05/1916.

35. DEVOTO, Fernando y FERNÁNDEZ, Alejandro, “Mutualismo étnico...”, Op. Cit., p. 143. ese sentido. Moris, además de contar con una destacada actuación en la Sociedad "Unione e Mutuo Soccorso", donde ejerció como Secretario en 1880, fue $2^{\circ}$ Jefe del Archivo General de la Provincia y presidente de las asociaciones "Reduci de la Patrie Battaglie e Congedati" y de la Sociedad Filarmónica Italiana. También los miembros de la asociación mutual española transitaron por diversos espacios asociativos y alcanzaron gran protagonismo en la vida económica, social, cultural y política de la provincia. Por ejemplo, Luis Remis, presidió la mutual española en 1897 y desde 1904 a 1911, fundó una influyente curtiembre, fue presidente de una fábrica de calzados y de importantes compañías y formó parte de comités de bancos y bolsas de comercio.Por su parte, Paulino Rodríguez Marquina presidió la mutual española en 1901, 1902 y 1903 y ocupó cargos claves como la Dirección de Estadística de la Provincia, entre 1895 1915.36

Otra cuestión que interesa sugerir remite a la definición más extendida en el estudio del liderazgo étnico: aquella que -como sostiene Núñez Seixas- identifica "la naturaleza del liderazgo con el ejercicio de funciones directivas en instituciones étnicas". ${ }^{37}$

Por último, quisiera proponer que el entramado de relaciones inter-asociativas y con los poderes públicos no excluyó la presencia de conflictos, lo cual no tiene nada de extraño en la medida que las asociaciones sufrían a lo

36. BOLOGNINI, Víctor Hugo y CURIA DE VILLECCO, María Elena, Del otro lado del mar..., Op. Cit., pp. 236-254.

37. Xosé NÚÑEZ SEIXAS sugiere que esta definición del líder étnico es "la opción teórica que presenta menos problemas hermenéuticos y de identificación del objeto de análisis”. NÚÑEZ SEIXAS, Xosé Manoel, "Modelos de liderazgos...", Op. Cit., pp. 23-24. 
largo de su vida institucional -más aún si ésta era prolongada como fue el caso de la Sociedad Española de Socorros Mutuos- numerosos cambios, reacomodos y enfrentamientos. En ese contexto, y como era usual en el mundo del mutualismo, el grueso de los problemas surgía en torno a la figura de los dirigentes, quienes tenían a su cargo decisiones claves. En los casos más extremos las críticas y las impugnaciones a los directivos podían confluir en su renuncia. Esto fue lo que pasó, por ejemplo, a mediados de 1916, cuando tras persistentes cuestionamientos, los miembros de la comisión directiva de la Sociedad Española de Socorros Mutuos resolvieron presentar su renuncia colectiva. De acuerdo con la lectura de las fuentes, es posible afirmar que esta decisión se originó en problemas relacionados con el manejo de los fondos económicos destinados a comprar el terreno para construir el Hospital y Parque Español. Asimismo, la acusación que recibieron quienes conducían los destinos de la mutual acerca de la falta de eficacia en la organización de los festejos dignos para conmemorar el próximo Centenario se vislumbró como otra causa de peso para fomentar dicha renuncia. ${ }^{38}$

\section{Las fiestas de las comunidades de inmigrantes}

Festejar las efemérides centrales del calendario patriótico de sus lugares de origen, conmemorar las fiestas religiosas y participar de las celebraciones cívicas del país

38. ASE, Acta No 54, Sesión Ordinaria, Libro de Comisiones Directivas, 12/06/1916 y ASE, Acta No

58, Sesión Ordinaria, Libro de Comisiones Directivas, 04/07/1916. que los había acogido, formaba parte central del mundo asociativo étnico. De este tema nos ocuparemos en este apartado. Para ello, tomaremos como referencias dos grandes celebraciones: el aniversario de la Toma de la Bastilla, evocado cada 14 de julio por los inmigrantes franceses, y el aniversario del 20 de setiembre, cuando los italianos recordaban la unidad política de su país. Posteriormente, nos ocuparemos de los festejos de la colectividad española en Tucumán, centrándonos en el caso de las romerías.

Cada 14 de julio, la colectividad francesa residente en la provincia se preparaba para evocar una fecha trascendental: la toma de la Bastilla. Mediante la formación de comisiones, la comunidad inmigrante asumía la organización de la fiesta que, tal como propone Mariana Feyling, reunía a los integrantes de la colectividad francesa y a la población en general en un ámbito de encuentro que fomentaba la interacción entre franceses y habitantes nacidos en Argentina. Desfile de antorchas, baile, teatro y kermesse eran algunos de los números que incluía el festejo. ${ }^{39}$

No ocultaba la prensa local su simpatía y admiración frente a la comunidad francesa de Tucumán. En el marco de la fiesta de julio de 1912, el diario El Orden aseguraba

Con gran entusiasmo celebró ayer la colectividad francesa el glorioso aniversario de la toma de la Bastilla. Las fiestas han servido para poner de manifiesto una vez más los lazos fraternales que unen a los miembros de la prestigiosa colonia y el noble espíritu de solidaridad cuando se trata

39. FEYLYNG, Mariana, "La inmigración francesa...", Op. Cit., p. 91. 
de rendir un homenaje a la querida patria ausente. $^{40}$

Estas muestras de admiración a los franceses se inscribían dentro de la amplia estima que tenía para un influyente sector de la población local la cultura de Francia. Desde esa perspectiva que valoraba lo francés, la prensa relataba las distintas actividades que tuvieron lugar durante el festejo de la efeméride. Los típicos saludos a las autoridades diplomáticas, en este caso al agente consular de Francia: el Sr. Emilio Bec, sumados al brindis entre profesores y estudiantes en el colegio francés y, finalmente, el banquete desplegado en el hotel París fueron los principales actos de esta fiesta, a la cual asistieron también las principales autoridades de la provincia.

A su vez, la comunidad francesa invitaba a sus fiestas a otros contingentes de inmigrantes, especialmente a belgas y suizos, a quienes, como ya señalamos en la sección anterior, aceptaba como socios en su mutual. Asimismo, acostumbraba a convocar a los ingleses a sus celebraciones.

Por su parte, los italianos canalizaban todos sus esfuerzos en la celebración del 20 de setiembre, cuando se recordaba la unidad política del país. Sobre esta fiesta y sus características, me gustaría plantear algunas consideraciones. La primera, que al igual que en el caso de los franceses, la cercanía de la efeméride italiana alentaba la creación de comisiones encargadas de preparar todas las actividades que formarían parte de la fiesta. Además, resulta importante señalar que en esas reuniones las mujeres desempeñaron un lugar central, ya que integraron muchas de las comisiones que tenían a su cargo la organización de los

40. El Orden, Tucumán, 15/7/1912. números de entretenimiento que incluían los festejos, tales como el bazar, la rueda de la fortuna, las argollas y el sport. ${ }^{41}$ Otra cuestión que me interesa destacar se relaciona con la eficacia de las conmemoraciones para fomentar los vínculos entre los países de origen y de acogida de los inmigrantes, así como entre los miembros de ambas orillas. Bajo esa óptica, podemos interpretar las consideraciones de la prensa periódica sobre el aniversario de la unidad italiana.

Tiene nuestro país especiales motivos para acompañar a Italia en sus regocijos. Hay, casi diríamos una comunidad de intereses entre Italia y la Argentina y si nosotros enviamos a la nación amiga nuestros votos, envíanos ella en cambio sus hijos que esforzada y denodadamente van poblando y animando montes y llanuras, aportando el contingente de sus brazos y de su sangre a nuestras luchas de progreso y a la gestación del tipo nacional. Por eso cada aniversario argentino y en cada aniversario italiano que bien puede decirse que todas las glorias nacionales se trasuntan, argentinos e italianos en un solo abrazo se confunden. ${ }^{42}$

Junto con las expresiones de fraternidad entre Argentina e Italia, así como entre sus habitantes, las celebraciones patrióticas italianas revelaron la importancia otorgada a las prácticas de solidaridad por parte de los integrantes de la colectividad. Estas manifestaciones se demostraban mediante la ayuda a los grupos humildes de la ciudad. De esta forma, era habitual que en los festejos del 20 de Setiembre se incluyera el reparto de pan y de carne a los habitantes pobres, tal como sucedió en la celebración de 1912, cuando la distribución de ayuda comenzó en

41. El Orden, Tucumán, 23/8/1912 y 13/9/1912.

42. El Orden, Tucumán, 20/1/1912. 
la mañana del 20 de setiembre de ese año. En esa ocasión, los festejos siguieron con la feria de beneficencia que tuvo lugar en la sede de la Sociedad Italiana durante la tarde de ese día y finalizaron con el concierto de gala desarrollado en la casa de Italia. Un banquete oficial en el bar Centenario, al que concurrirían las autoridades de la provincia, un concierto nocturno al día siguiente (domingo 22 de setiembre) y un suntuosos baile de gala previsto para el sábado 28 completaban los actos programados para el festejo. ${ }^{43}$

Ya en 1916, en plena Guerra Mundial, la fiesta de la unidad italiana demostró una vez más la solidaridad y ayuda de los italianos que en esa ocasión decidieron colaborar con las familias de los reservistas que habían ido a la guerra mediante la entrega de un canasto con comestibles. Asimismo, la conmemoración incluyó los usuales saludos al agente consular y los impartidos a los representantes de las naciones aliadas, alentados por la coyuntura bélica del momento. La participación de una banda de música que recorrió las calles de la ciudad y un concierto de gala en la casa de Italia formaron parte de los actos desarrollados para dicha fiesta. ${ }^{44}$

Resulta importante apuntar que, tal como se desprende del examen de las fuentes, principalmente de las narraciones difundidas por la prensa, además de evocar las efemérides centrales del calendario asociativo, patriótico y religioso de las comunidades de inmigrantes, las fiestas se organizaban para recaudar fondos destinados a terminar una obra de infraestructura, por ejemplo un local social, un hospital, una escuela o un panteón en

43. El Orden, Tucumán, 12/9/1912.

44. El Orden, Tucumán, 20/9/1916. el cementerio. En tanto los ingresos de las mutuales obtenidos por parte de las cuotas de los asociados eran muchas veces insuficientes para cubrir todos los gastos de la vida asociativa, principalmente para afrontar el costo de la distribución de los socorros, las fiestas representaban una oportunidad eficaz para obtener mayores recursos. En esa dirección, la realización de eventos culturales, sociales y deportivos en los cuales se cobraban entradas y/o se vendían productos podía resultar una salida auspiciosa.

En ese contexto, podemos recuperar las celebraciones de la comunidad española. Veamos algunos ejemplos. Al despuntar febrero de 1914, la Sociedad Española de Socorros Mutuos puso en marcha un festival deportivo destinado a conseguir recursos para construir un hospital, anhelo central de la mutual. El evento tuvo lugar en el club San Martín, cedido para la ocasión por el presidente del Consejo General de Educación, e incluyó concursos y juegos hípicos, vuelos a cargo de un aviador que llegaría especialmente a la ciudad de San Miguel de Tucumán para participar de los actos, carreras de bicicletas y de motocicletas y un programa novedoso de juegos atléticos. Por su parte, las autoridades de la provincia ya habían asegurado su asistencia a través de la presidencia honoraria del torneo por parte de funcionarios de gobierno de la más alta jerarquía, tales como el gobernador, el intendente municipal y el jefe del comando de la $5^{\circ}$ región. ${ }^{45}$

La presencia de los gobernantes en las fiestas de la comunidad española no era nada extraña.Por el contrario, y al igual que en las celebraciones de otras colectividades, los poderes públicos se

45. El Orden, Tucumán, 2/02/1914. 
hacían presentes, lo cual demostraba el apoyo y el compromiso oficial con los actos de las comunidades. En esos parámetros podemos situar también la celebración que tuvo lugar en 1914 y que incluyó un baile infantil de disfraz el primer domingo de carnaval. La Comisión de Damas Protectoras de la Sociedad Española de Socorros Mutuos desempeñó un papel fundamental en preparar la entrega de premios tanto para las parejas que resultaran ganadoras de los bailes criollos y españoles, como para los niños que se presentaran con los trajes regionales o de fantasía más vistosos. ${ }^{46}$ Una noticia sobre el baile de carnaval, acompañada de una fotografía alusiva fue publicada después por el diario El Orden. De acuerdo con esa información, sabemos que en los salones de la mutual española se desplegó el baile de fantasía, el cual contó con la asistencia del gobernador de la provincia, el Dr. Ernesto E. Padilla, del ministro de gobierno, del jefe de policía y del comisario de órdenes. ${ }^{47}$

Además, otras sociedades de inmigrantes españoles organizaron fiestas y actividades de naturaleza social, cultural, deportiva, etc. Tal fue el caso de las asociaciones de carácter regional, formadas mayoritariamente desde comienzos del siglo $\mathrm{XX}$, según consignas principalmente de naturaleza cultural. Una muestra en ese sentido fue la velada literariomusical del Círculo Artístico Valenciano para inaugurar su nuevo local en la calle 9 de julio al 100. En octubre de 1914 se desarrolló esta fiesta que culminó con un baile social al que habían sido invitadas numerosas familias de la colectividad española. ${ }^{48}$ Paralelamente, el recientemente formado Centro Cataluña

46. El Orden, Tucumán, 23/01/ 1914.

47. El Orden, Tucumán, 25/02/ 1914.

48. El Orden, Tucumán, 9/10/ 1914.

34 preparó una velada familiar ${ }^{49}$ poco tiempo después, el ya mencionado Círculo Valenciano convocó a un gran baile familiar para recordar el descubrimiento de América. ${ }^{50}$

Pero si todas estas fiestas eran importantes, las que más brillo alcanzaban eran las romerías que lograban traspasar las fronteras étnicas al involucrar a la sociedad tucumana en su conjunto. $\mathrm{Al}$ respecto resultó muy sugerente el análisis de María Liliana Da Orden sobre la evolución de las romerías en Mar del Plata. De acuerdo con la autora, dichas fiestas permitían

...consolidar vínculos y anudar otros con los círculos más elevados de la esfera nacional, tanto españoles como criollos. De ahí el despliegue de "bombas", fuegos artificiales y música que demostraban ante semejantes espectadores la influencia de las autoridades de la colectividad en Mar del Plata. Más allá de su repercusión efectiva, en la aspiración de los organizadores se ponía de manifiesto una de las dimensiones de un proceso de autoafirmación hacia la sociedad receptora que también se observa en otros puntos del país. ${ }^{51}$

Y no solo para los dirigentes étnicos eran importantes las fiestas. "También para la elite nativa estas prácticas fueron adquiriendo importancia, de ahí los ofrecimientos y donativos que con el tiempo realizaron para estas fiestas tanto terratenientes como importantes empresarios y políticos del lugar". 52

49. El Orden, Tucumán, 9/10/ 1914.

50. El Orden, Tucumán, 12/10/ 1915.

51. DA ORDEN, María Liliana, "Romerías españolas e inserción social en tiempos de la inmigración masiva a la Argentina, en A grileira. Revista de Musicología y Archivo Histórico de la Fundación Xeito Novo de Cultura Gallega, Buenos Aires, 2003, N 5.

52. Ibídem. 
Estas facetas de las fiestas se observan también en nuestro estudio de las romerías en Tucumán. A manera de un estudio microscópico, me detendré en las fiestas de 1912 y comenzaré con la información proporcionada por el diario $E l$ Orden que en setiembre de ese año publicó una noticia en la cual comentaba detalladamente los preparativos de la celebración. Más adelante, el diario difundió una extensa nota, acompañada de una fotografía, donde comentaba que la fiesta comenzó con una misa que reunió a la colectividad española con funcionarios de gobierno. Tal como aseguraba El Orden, una vez concluida la ceremonia religiosa se sirvió un lunch al cual asistieron las familias argentinas y españolas, además de las autoridades locales. Tangos de confraternidad argentino-española, sumados a los posteriores juegos en el campo de las romerías, música en las carpas y el baile en la carpa oficial retrataban el desarrollo de la fiesta. Grandes elogios brindó el diario a la fiesta que alcanzó una amplísima convocatoria a juzgar por las 2000 entradas vendidas. ${ }^{53}$

La revisión de los documentos resguardados en la Sociedad Española de Socorros Mutuos demostró la centralidad otorgada a las romerías. Todos los años se formaban comisiones especiales para su preparación, la cual demandaba varios meses y en el transcurso de este tiempo se reunían los integrantes de la mutual que habían sido elegidos para formar parte de dicha comisión especial, denominada “de romerías". Estas comisiones llevaban su propio libro de actas, fuentes que nos permiten recuperar y analizar las prácticas y discursos que involucraron la organización de las fiestas. De esta forma podemos volver a las romerías de 1912 y completar el cuadro proporcionado por la prensa. Tal como se desprende de la

53. El Orden, Tucumán, 9/9/1912. lectura de las actas, el 14 de junio de ese año se efectuó la primera reunión para organizar las romerías en la sede de la Sociedad Española de Socorros Mutuos. En dicho encuentro se constituyó la comisión organizadora de las fiestas, además de una comisión que tendría a su cargo la tarea de contratar la estudiantina de la provincia Buenos Aires. Para ello, decidieron pedir presupuesto a distintos maestros ${ }^{54} \mathrm{y}$, hasta el momento, contaban con dos propuestas, la del maestro Basilio Bassi que solicitaba 5000 pesos, además del pago de los pasajes pagados, y la del Sr. Rivera bajo las mismas condiciones. ${ }^{55}$

Diversos temas relacionados con la organización de las romerías se discutieron en las reuniones de la comisión especial, tales como propuestas a favor y en contra de los bailes en las carpas, ${ }^{56}$ el lugar en donde se celebraría la función inaugural de las fiestas (se resolvió que sería en la sede de la Sociedad Española de Socorros Mutuos), la contratación de la estudiantina más conveniente y la publicación de avisos en la prensa local para informar sobre el alquiler carpas. ${ }^{57}$ Paralelamente, la lectura de las actas de la Comisión de Romerías permitió observar toda la serie de trámites que debían realizarse para la puesta en marcha de las fiestas, gestiones que incluían invariablemente la solicitud de los permisos correspondientes a las autoridades, tanto al jefe de policía como al

54. ASE, Libro de Actas de la Comisión de Romerías, Sesión No 1, Año 1912.

55. ASE, Libro de Actas de la Comisión de Romerías, Sesión No 2, Año 1912.

56. ASE, Libro de Actas de la Comisión de Romerías, Sesión No 3, Año 1912.

57. ASE, Libro de Actas de la Comisión de Romerías, sesiones No 6, 7 y 11, Año 1912. 
intendente municipal..$^{58}$ Finalmente, el examen de estos documentos remite a una cuestión de especial interés para este trabajo: el tejido de vínculos inter-asociativos. Muestras de lo anterior fueron, por ejemplo, las numerosas cartas que recibían y enviaban los miembros de la Sociedad Española de Socorros Mutuos que integraban la Comisión de Romerías. Por ejemplo, en el transcurso de las asambleas desarrolladas para organizar la fiesta de ese año de 1912, algunas de las notas que se leyeron se referían a las invitaciones enviadas por la Comisión de Romerías a las autoridades provinciales, así como al vicecónsul español, para que asistieran a la misa de Campaña que tendría lugar en el campo de las romerías. La Sociedad de Beneficencia y diversas asociaciones de ayuda mutua, tanto argentinas como extranjeras, fueron a su vez invitadas a dicha misa. ${ }^{59}$ Entre las notas que recibían y enviaban los integrantes de la Comisión de Romerías pudimos detectar también la proveniente del Centro Catalá en la cual aceptaba la propuesta para que su coro tomara parte en las romerías. También, localizamos la correspondencia dirigida a asociaciones prestigiosas del medio, como la Sociedad Francesa, la Sociedad Italiana, la Sociedad Argentina, el Centro Catalán de Cultura y la Sociedad Sarmiento, para asistir a la sede de la Sociedad Española de Socorros Mutuos y desde allí partir en corporación a la misa de inauguración de las romerías. ${ }^{60}$

58. ASE, Libro de Actas de la Comisión de Romerías, Sesión No 12, Año 1912.

59. ASE, Libro de Actas de la Comisión de Romerías, Sesión No 19, Año 1912.

60. ASE, Libro de Actas de la Comisión de Romerías, Sesión No 14, Año 1912.
En síntesis, el análisis de las actas de las comisiones de romerías formadas durante las primeras décadas del siglo $\mathrm{XX}$ permite sugerir la trama de relaciones asociativas de la cual participaba la comunidad de inmigrantes españoles en Tucumán a través de su principal institución, la Sociedad Española de Socorros Mutuos. Al analizar las romerías pudimos observar que líderes étnicos de distinta procedencia nacional, referentes de la elite local y autoridades de gobierno participaban de las fiestas. Esta participación demostraba la importancia otorgada por la dirigencia étnica de otras colectividades de inmigrantes, los gobernantes y sectores dominantes a la Sociedad Española de Socorros Mutuos.

El interés por entablar y sostener vínculos con la mutual española se evidenciaba también mediante otra práctica frecuente que tenía lugar en el transcurso de los preparativos para organizar las romerías: las donaciones. En esa dirección, podemos mencionar los numerosos obsequios que recibieron las comisiones de romerías a lo largo del tiempo, tal como se reveló, por ejemplo, en las reuniones previas a las fiestas de 1911, cuando las notas enviadas por gobernantes, comerciantes y banqueros dieron cuenta de los regalos enviados a la Comisión de Romerías: como un bronce de estatua con reloj por parte del gobierno provincial, un alhajero otorgado por el gerente del Banco Alemán, un estuche con un tintero donado por el Diario del Norte y un cajón de vinos proveniente de la Confitería "El Águila". ${ }^{61}$

Pero no solo a los demás les interesaba entablar lazos con la Sociedad Española de Socorros Mutuos. Los objetivos eran recíprocos y la

61. ASE, Libro de Actas de la Comisión de Romerías, Sesión No 20, Año 1911. 
mutual española dio sobradas muestras de su afán por sostener y propiciar vínculos con los poderes públicos y con otras sociedades. En esa línea, participó en las celebraciones patrióticas nacionales y provinciales, así como en las fiestas motorizadas por otras asociaciones.

Para finalizar, durante el periodo estudiado se observó el desarrollo de un tejido de vínculos inter-asociativo favorecido por la membrecía común a distintas asociaciones por parte de los líderes étnicos. Los lazos entre las asociaciones de una misma colectividad inmigrante se combinaron también con las relaciones entre las sociedades de extranjeros de distinta naturaleza y procedencia. Además, los dirigentes de las comunidades de inmigrantes participaron activamente de la escena pública y desarrollaron numerosas conexiones con los poderes políticos, económicos, culturales, etc. Las fiestas constituyeron espacios excepcionales para fortalecer estos lazos. Además de los dirigentes mencionados en el trabajo podemos identificar un abundante conjunto de nombres que sobresalieron en el universo mutual, se relacionaron estrechamente con los principales referentes del poder político y económico, al tiempo que ejercieron gran influencia en el campo educativo, de la cultura, del comercio y de la industria, sobre todo de la principal actividad productiva de la provincia: la agroindustria azucarera. ${ }^{62}$

62. Los ejemplos son abundantes. De la comunidad italiana podemos mencionar a Inocencio Liberani, Alfredo Puccio, José Benci, Carlo Battaglini, Andrea Carpinacci, Angel Paganelli, Pedro Stuchi, Pedro Storni, Juan Arena e Isaía Senestrari, Eduardo Bossi y Augusto Mosna. Entre los inmigrantes españoles, Enrique Emerich, Eliseo Cantón, Manuel García Fernández, Gerardo y Rogelio Costantini, Desiderio de Aguayo, Guillermo y Miguel Caballer, Emilio Calderón, José Martí, Vicente Llorc, Agustín Begoña y Manuel Carrasco. Ver: BOLOGNINI, Víctor Hugo y CURIA

\section{La recepción a los viajeros por parte de las comunidades de inmigrantes}

La visita a Tucumán de renombradas figuras europeas provenientes del campo intelectual, artístico, cultural, político o económico representaba una ocasión especial para visibilizar el desarrollo de un tejido asociativo en la provincia. En especial, eran las comunidades de inmigrantes agrupadas a través de sus principales instituciones y encabezadas por sus dirigentes quienes desempeñaban un papel central en las prácticas desplegadas para recibir a los viajeros.

Por lo general, los diplomáticos, comerciantes, industriales, príncipes, artistas, intelectuales y líderes políticos que llegaban a Tucumán permanecían uno o dos días y participaban de una apretada agenda de actividades compartida con funcionarios de gobierno, representantes políticos, grupos empresarios y líderes étnicos, figuras que mayor protagonismo alcanzaban al interactuar directamente con los viajeros y ocupar un lugar preponderante en los eventos organizados durante sus estadías. Por su parte, la prensa se hacía eco de estas estancias y dedicaba amplio espacio en sus páginas a narrar con sumo detalle los actos programados para la recepción de los afamados huéspedes.

Esto fue lo que sucedió, por ejemplo, con la visita del Barón de Gugliemini, quien estuvo en San Miguel de Tucumán a principios de 1912. Gugliemini, conocido por su trayectoria en el parlamento italiano, dictó una conferencia en la Sociedad Italiana de Socorros Mutuos. Según El Orden, "con fervoroso sentimiento" destacaba el disertante los "meritos especiales"

DE VILLECCO, María Elena, Del otro lado del mar..., Op. Cit., pp. 236-248. 
de los "principales colaboradores de la unidad italiana: Mazzini, Cavour, Victorio Manuel II y Garibaldi”, este último llamado por el Barón "el arcángel de la libertad". De acuerdo con la prensa, las palabras del disertante conmovieron al auditorio que le brindó un fuerte aplauso. La excelente acogida del público tucumano y los generosos elogios del Barón de Guglielmini a la sociedad tucumana y al adelanto de la provincia ${ }^{63}$ sintetizaban el éxito de la visita.

Un itinerario usual de los viajeros era conocer los lugares emblemáticos de Tucumán. En esa dirección una consigna obligada era visitar los ingenios azucareros que constituían los principales establecimientos productivos de la provincia. Otros destinos característicos de los visitantes eran los monumentos históricos más relevantes de Tucumán, como la Casa Histórica, lugar donde se declaró la Independencia el 9 de julio de 1816. Así, cuando en 1924 el heredero de la Corona Italiana, el príncipe Humberto de Saboya, hijo del rey Víctor Manuel III, estuvo en Tucumán "visitó la Casa Histórica, presenció un desfile militar y de escolares, estuvo en el ingenio San Pablo y en Villa Nougués. Asistió a una recepción en la Casa de Italia y a un gran banquete en la legislatura, y descubrió, en los jardines del Rectorado de la Universidad, un busto en bronce de Dante Alighieri". ${ }^{64}$ Una gran recepción realizó la comunidad italiana al príncipe, a quien que le obsequió una medalla especialmente acuñada en su homenaje. ${ }^{65}$

63. El Orden, Tucumán, 27/01/1912 y 29/01/1912.

64. PÁEZ DE LA TORRE, Carlos, "Medalla para el príncipe. Visita de Humberto de Saboya a Tucumán en 1924, “Apenas Ayer”, La Gaceta, Tucumán, 3/05/2008.

65. Ibídem.
Además de aproximarse a los lugares más representativos de la provincia, los viajeros aprovechaban su estadía para descubrir las empresas, obras de infraestructura $y$ expresiones artísticas que revelaban la huella de los inmigrantes. De esta forma, durante su estancia en San Miguel de Tucumán, el ingeniero Luis Albertini, delegado del Ministerio de Comercio e Industrias de Francia y de la Alianza Francesa en América Latina,

...visitó los ingenios, cuya potencialidad admira y las principales obras de arte con que se va enriqueciendo la provincia, sobre todo las que construyen la hidro-eléctrica y que será de incalculables ventajas para nuestra capacidad industrial. Respecto de la colectividad francesa, el señor Albertini no ocultó las simpatías vivísimas que por ella siente y los entusiasmos que le ha suscitado para el desempeño de su misión, la sana y noble cordialidad que une a sus connacionales en esta capital. ${ }^{66}$

De acuerdo con el relato de la prensa, sabemos que en el viceconsulado de Francia se desarrolló un encuentro entre el visitante y un amplio número de inmigrantes franceses que simpatizaban con la patriótica asociación (en referencia a la Alianza Francesa). ${ }^{67}$ Como resultado de esta reunión, el viajero destacó la cultura y la laboriosidad de los franceses que vivían en la provincia, así como el espíritu de progreso y el noble amor que sentían por la Argentina. ${ }^{68}$
66. El Orden, Tucumán, 4/09/1912.

67. El Orden, Tucumán, 27/08/1912 y 4/09/1912.

68. El Orden, Tucumán, 4/09/1912. 


\section{Consideraciones finales}

El trabajo planteó una aproximación al universo del mutualismo étnico en Tucumán entre mediados del siglo XIX y primeras décadas del XX. Apoyado principalmente en la lectura de las fuentes de las asociaciones -y completada esta información con los datos obtenidos de la prensa- se exploró diversos aspectos concernientes a la vida de las mutuales. El punto de partida fue el examen de las prácticas de socorro mutuo, los debates y las discusiones que desarrollaron sus miembros reunidos en asambleas de socios y en sesiones de comisiones directivas. En ese marco, la revisión de las actas de asambleas y los libros de comisiones directivas reveló la influencia de los líderes en la praxis asociativa, que a su vez potenciaba tales liderazgos y apuntalaba el desarrollo de una trama de vínculos interasociativos y con el poder público.

La conformación y expansión de estos lazos encontró una ocasión especialmente propicia en las fiestas puestas en marcha por las mutuales para recordar efemérides centrales de la patria de origen, celebrar aniversarios de la vida asociativa o conmemorar festividades asociadas al calendario católico. Dichas celebraciones representaban asimismo una oportunidad sumamente valorada para recaudar fondos económicos $\mathrm{y}$, por esa vía, solventar los proyectos más onerosos del funcionamiento institucional como podían ser la construcción de un hospital, un salón social, la edificación del panteón en el cementerio o la edificación de una escuela.

Estrechamente asociados estos fines económicos con los propósitos de estimular y conservar las tradiciones y la cultura de las comunidades inmigrantes, las fiestas eran facetas medulares de la vida asociativa, donde los participantes interactuaban y compartían experiencias en un ambiente de esparcimiento cargado de símbolos y rituales vinculados con cada comunidad. Por su parte, los dirigentes de las asociaciones, en su papel de figuras visibles de las colectividades, desempeñaban un rol fundamental en las fiestas al actuar como intermediarios entre su comunidad, las autoridades políticas y otros grupos de poder local. Posiblemente, eran quienes más beneficios obtenían al conseguir mediante las celebraciones una mayor cercanía con los sectores influyentes de Tucumán, que podían provenir de otros colectivos de inmigrantes, el poder político, económico, etc., y manifestaban, a su vez, notable interés por afianzar estos lazos.

Este valor asignado a las fiestas puede explicar el esmero y la dedicación con la que año a año se organizaban comisiones especiales para ocuparse de cada detalle inherente a las mismas. En esa línea se destacaron las romerías españolas, ejemplo contundente no sólo de la centralidad que ocuparon las celebraciones para la comunidad inmigrante sino también de la importancia otorgada por la sociedad local a las mismas.

Otro vértice clave de la vida asociativa fue la visita de renombradas figuras, por lo general europeos que se destacaban en la arena cultural, social, política o económica de sus países de origen y cuya estancia en Tucumán servía para fomentar múltiples lazos e intercambios. A través de detallados programas que se confeccionaban para aprovechar al máximo cada visita, los viajeros conocían lugares e instituciones emblemáticas de la provincia, al tiempo que compartían diversas actividades con los sectores más 
representativos a nivel local. Paralelamente, las comunidades de inmigrantes podían conocer $\mathrm{y}$ acercarse a los visitantes, quienes actuaban como un puente capaz de favorecer la difusión de creencias, opiniones e ideas entre Europa y América, conectando así el lugar de origen de los inmigrantes con el nuevo espacio donde forjaban su vida. Una vez más, fueron los dirigentes étnicos, quienes junto con las autoridades políticas y los grupos de poder (económico, social, cultural, etc.), ocuparon lugares de mayor visibilidad y centralidad. Con lo cual, es factible pensar que tales encuentros robustecían su poder en el seno de la comunidad inmigrante y proyectaban su liderazgo al resto de la sociedad. Asimismo, no está de más insistir en la posible eficacia de las experiencias compartidas durante las estancias de los viajeros para favorecer los vínculos y los sentimientos de pertenencia de las comunidades de inmigrantes con sus países de origen.

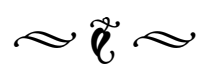

Recibido: 15-11-2016

Aceptado: 13-03-2017

Publicado: 06-06-2017 


\section{Bibliografía}

BERTONI, Lilia Ana, Patriotas, cosmopolitas y nacionalistas. La construcción de la nacionalidad argentina a fines del siglo XIX, Fondo de Cultura Económica, Buenos Aires, 2001.

BJERG, María, Historias de la inmigración en la Argentina, Edhasa, Temas de la Argentina, Buenos Aires, 2009.

BOLOGNINI, Víctor Hugo y CURIA DE VILLECCO, María Elena, Del otro lado del mar. Tucumán, destino final, Facultad de Filosofía y Letras, Instituto de Historia y Pensamiento Argentino, Tucumán, 2006.

BRAVO, María Celia, Campesinos, azúcar y politica: cañeros, acción corporativa y vida politica en Tucumán (1895-1930), Prohistoria, Rosario, 2008.

BRAVO, María Celia y FERNÁNDEZ, Sandra (coordinadoras) Formando el espacio público: asociacionismos y política. Siglos XIX y XX, Editorial de la Universidad Nacional de Tucumán,Tucumán, 2014, pp. 7-24.

CENTRO DE HISTORIA Y PENSAMIENTO ARGENTINO, La inmigración en Argentina, Facultad de Filosofía y Letras, San Miguel de Tucumán, 1979.

CURIA DE VILLECCO, María E. y BOLOGNINI, Víctor Hugo, Inmigración en Tucumán, Facultad de Filosofía y Letras, Instituto de Historia y Pensamiento Argentino,Tucumán, 1991.

DA ORDEN, María Liliana, "Romerías españolas e inserción social en tiempos de la inmigración masiva a la Argentina, en A grileira. Revista de Musicología y Archivo Histórico de la Fundación Xeito Novo de Cultura Gallega, Buenos Aires, 2003, N 5.

DEVOTO, Fernando, "La experiencia mutualista italiana en Argentina: un balance”, en DEVOTO, Fernando y MÍGUEZ, Eduardo J. (compiladores) Asociacionismo, trabajo e identidad étnica. Los italianos en América Latina en una perspectiva comparada, Centro de Estudios Migratorios Latinoamericanos, Centro Studi Emigrazione e Instituto de Estudios Históricos y Sociales, Buenos Aires/Roma, 1992, pp. 169-185.

DEVOTO, Fernando y ROSOLI, Gianfausto (editores) La inmigración italiana en la Argentina, Biblos, Colección La Argentina plural, Buenos Aires, 2000, pp. 141-164.

DEVOTO, Fernando, Historia de los italianos en la Argentina, Biblos, Colección La Argentina plural, Buenos Aires, 2008 [1 $1^{\mathrm{a}}$ edición 2006].

DEVOTO, Fernando y FERNÁNDEZ, Alejandro, "Mutualismo étnico, liderazgo y participación política. Algunas hipótesis de trabajo”, en ARMUS, Diego (compilador) Mundo urbano y cultura popular, Sudamericana, Buenos Aires, 1990.

FERNÁNDEZ, Sandra y VIDELA Oscar (compiladores) Ciudad oblicua. Aproximaciones e intérpretes de la entreguerra rosarina, La Quinta Pata y Camino Ediciones, Rosario, 2008.

FEYLYNG, Mariana, “La inmigración francesa temprana en Tucumán: 1830-1880”, en Travesia, Tucumán, 2004, N 7/8, pp.73-101. Disponible en: <http://www.travesia-unt.org.ar/pdf/travesia78_3.pdf> 
FRID, Carina "Las opciones educativas de la comunidad italiana en Rosario: las escuelas mutualistas y el colegio Salesiano (1880-1920)”, en DEVOTO, Fernando y MÍGUEZ, Eduardo J. (compiladores) Asociacionismo, trabajo e identidad étnica. Los italianos en América Latina en una perspectiva comparada, entro de Estudios Migratorios Latinoamericanos, Centro Studi Emigrazione e Instituto de Estudios Históricos y Sociales, Buenos Aires/Roma, 1992, 101-114.

GARCÍA DE SALTOR, Irene, CURIA DE VILlECCO, María Elena, BOLOGNINI, Víctor Hugo, UGARTE DE GALLO, Alicia y PIOSSEK DE ZUCCHI, Lucía, Transformaciones en la Argentina Aluvial, en PROGRAMA DEL CONSEJO DE INVESTIGACIONES DE LA UNIVERSIDAD NACIONAL DE TUCUMÁN, "La Argentina ante transformaciones del mundo contemporáneo desde la perspectiva del NOA, Serie 2, Facultad de Filosofía y Letras, Instituto de Historia y Pensamiento Argentino, Tucumán, 1995.

GARGIULO, Cecilia, La Sociedad de Beneficencia en la politica social. Tucumán, 1874-1917, Tesis Doctoral, Universidad Nacional de Tucumán, 2012.

GJERDE, Jon, "Identidades múltiples y complementarias. Inmigrantes, liderazgos étnicos y el Estado en Estados Unidos”, en BERNASCONI, Alicia y FRID, Carina, De Europa a las Américas. Dirigentes y liderazgos (1880-1960), Biblos, Colección La Argentina plural, Buenos Aires, 2006, pp. 63-79.

GONZÁLEZ BERNALDO, Pilar, "El momento mutualista en la formulación de un sistema de protección social en Argentina: socorro mutuo y prevención subsidiada a comienzos del siglo XX, en Revista de Indias, Madrid, 2013, V. LXXIII, pp. 157-192. Disponible en: <http://revistadeindias.revistas.csic.es/ index.php/revistadeindias/article/view/921/994> doi:<10.3989/revindias.2013.007>.

LANDABURU, Alejandra, "Organizaciones de la sociedad civil, trabajadores y empresarios azucareros. Tucumán, fines del siglo XIX y principios del XX”, ponencia presentada en X Jornadas Interescuelas/ Departamentos de Historia, Universidad Nacional de Rosario, Rosario, 2005.

LANDABURU, Alejandra, "Organizaciones de la sociedad civil en Tucumán a fines del siglo XIX y comienzos del XX: las sociedades mutuales”, en Actas VI Jornadas La Generación del Centenario y su Proyección en el Noroeste Argentino. 1900-1950, Centro Cultural Alberto Rougés, Fundación Miguel Lillo, Tucumán, 2006.

LENIS, María, Empresarios del azúcar. Corporaciones, politica y discursos. Tucumán (1894-1923), Imago Mundi, Buenos Aires, 2016.

MICHELETTI, María Gabriela, "Asociacionismo y espíritu étnico en Santa Fe a fines del siglo XIX", ponencia presentada en $X$ Jornadas Interescuelas/Departamentos de Historia, Universidad Nacional de Rosario, 2005.

NAESSENS, Sergio Francisco, La inmigración en Argentina en el siglo XX. Análisis de casos: japoneses, belgas y coreanos en Tucumán, Centro de Estudios de Asia y África, Facultad de Filosofía y Letras, Universidad Nacional de Tucumán,Tucumán, 2004.

NÚÑEZ SEIXAS, Xosé Manoel, "Modelos de liderazgos en comunidades inmigradas. Algunas reflexiones a partir de los españoles en América”, en BERNASCONI, Alicia y FRID, Carina (editoras) De Europa a las Américas. Dirigentes y liderazgos (1880-1960), Biblos, Colección La Argentina plural, Buenos Aires, 2006, pp. 17-41. 
ORTÍZ DE D’ARTERIO, Patricia, Las migraciones internacionales en la provincia de Tucumán, Serie Tesis, Instituto de Estudios Geográficos, Facultad de Filosofía y Letras, Universidad Nacional de Tucumán, Tucumán, 2004.

ORTÍZ REINA, Ana María, "Inmigrantes españoles en Tucumán. La Asociación Española de Socorros Mutuos y Beneficencia de Tucumán y la de Tafí Viejo", en PEDICONE DE PARELLADA, Elena (directora y compiladora) Espacio de Sinergia entre España y Tucumán, Universidad Nacional de Tucumán, Tucumán, 2013.

OTERO, Hernán, "El asociacionismo francés en la Argentina. Una perspectiva secular", en Estudios Interdisciplinarios de America Latina y el Caribe, Tel Aviv, 2010, V. XXI, No 2, pp. 123-150. Disponible en: <http://www7.tau.ac.il/ojs/index.php/eial/article/view/32/16>

OTERO, Hernán Gustavo, "Las escuelas étnicas de la comunidad francesa. El caso argentino, 1880-1950", en Anuario de Estudios Americanos, Sevilla, 2011, V. LXVIII, N 1, pp. 163-189. Disponible en: <http:// estudiosamericanos.revistas.csic.es/index.php/estudiosamericanos/article/view/536/540>

PÁEZ DE LA TORRE, Carlos, "Medalla para el príncipe. Visita de Humberto de Saboya a Tucumán en 1924, “Apenas Ayer”, La Gaceta, Tucumán, 3/05/2008.

SANTOS LEPERA, Lucía, "Asociacionismo y prácticas católicas en los años treinta: asociacionismo y prácticas católicas en los años treinta: la Acción Católica tucumana y la configuración del laicado", en VIDAL, Gardenia y BLANCO, Jessica (compiladoras) Estudios de la historia de Córdoba en el siglo XX, T. II, Ferreyra Editor, Córdoba, 2010, pp. 19-36.

TEITELBAUM, Vanesa, "El anarquismo en Tucumán: expresiones de protesta y rituales obreros, 19001912”, en Izquierdas, Santiago, 2016, N²8, pp. 66-93. Disponible en: <http://www.scielo.cl/scielo. php?script=sci_arttext\&pid=S0718-50492016000300003>

TEITELBAUM, Vanesa, "Veladas literario-musicales y manifestaciones públicas en la construcción del Primero de Mayo en Tucumán (Argentina), 1897-1925”, en Esboços - Revista do Programa de PósGraduação em História da UFSC, Florianapólis, 2015, V. XXII, N 33, pp. 170-197. Disponible en: <http://dx.doi.org/10.5007/2175-7976.2014v22n33p170>

TEITELBAUM, Vanesa, "Movilizaciones, dirigentes y conformación de una trama asociativa en el mundo del trabajo artesanal (Tucumán, 1890-1910)", en Theomai. Estudios Críticos sobre sociedad y desarrollo, Bernal, 2015, pp. 123-145. Disponible en: <http://revista-theomai.unq.edu.ar/NUMERO_31/6. Teitelbaum.pdf>

TEITELBAUM, Vanesa, "E1 Centro Cosmopolita de Trabajadores: un espacio de referencia del movimiento obrero en el norte argentino en los umbrales del siglo XX", en Estudios Sociales, Santa Fe, 2011, No 40, pp. 145-174. Disponible en: <http://bibliotecavirtual.unl.edu.ar/ojs/index.php/EstudiosSociales/ article/view/2676/3834>

TEITELBAUM, Vanesa, "Los centros obreros como ámbitos de cultura, protesta y política (Tucumán, 1895-1910)", en AA. VV., La clase obrera y el Centenario-1910- trabajos de investigación, Central de Trabajadores de la Argentina (CTA) y Programa de Investigación sobre el Movimiento de la Sociedad Argentina (PIMSA), CTA Ediciones, Buenos Aires, 2011. 
VIGNOLI, Marcela Sociabilidad y cultura politica. La Sociedad Sarmiento de Tucumán, 1880-1914, Prohistoria Ediciones, Rosario, 2015. 